\title{
Forged images lead to German inquiry
}

[MUNICH] In what appears to be Germany's first significant case of scientific fraud, two molecular biologists with rapidly growing reputations have been accused of fabricating data in papers published in leading journals.

Marion Brach, 37, a full professor at the University of Lübeck near Hamburg, is reported to have admitted falsifying results in four research papers while she was working in the laboratory of Friedhelm Herrmann at the Max Delbrück Centre for Molecular Medicine in Berlin in the early 1990s.

But Herrmann denies any knowledge that the data in the papers had been manipulated, even though he was a co-author on all four. Herrmann, 47, is one of Germany's leading gene therapy research scientists and a professor at the University of Ulm.

In the most brazen case, Brach, whose work concerns cytokines and multidrugresistance genes in relation to cancer therapy, is said to have admitted that she had "mixed and matched" computerized images from unrelated experiments, based on unrelated methodologies, to forge a new set of experimental data.

Local and national committees have been set up to investigate the extent of the alleged fraud in the pair's voluminous publication record, and to try to determine whether Herrmann was aware of it.

Details of the affair were made public last week in the German news magazine Focus. Both scientists are continuing their academic work. But all grant money to their laboratories has been suspended until the affair is resolved. Herrmann's positions on advisory boards to the Deutsche Forschungsgemeinschaft, Germany's research council, have also been suspended.

Herrmann and Brach have shared what has appeared to be a highly successful academic career. In the 1980s, both worked at Harvard University in the United States before returning to the University of Freiberg in Germany. In 1992 they moved to Berlin, where Hermann: denies Herrmann was full pro- knowing of fraud. fessor at the Free

University and a senior consultant at the university's Robert Rössle Cancer Centre.

Herrmann was also given laboratory space at Max Delbrück Centre, a national research centre set up in east Berlin after reunification, where he built up a research team of around 20 scientists. Brach was one of four group leaders in the team, a position that allowed her to gain the German qualification Habilitation, which is necessary to become a university professor.

In early 1996, Herrmann and Brach left Berlin for Ulm in west Germany, where Herrmann had better opportunities for his clinical and research activities.

Shortly afterwards Brach was offered a full professorship at the University of Lübeck. She is director of the university's new Institute of Molecular Medicine.

But the professional rise of both scientists was halted in March when investigations into the alleged fraud began. Researchers working with them in Berlin had for some time suspected that some data might have been fabricated, but had been reluctant to make a public complaint out of concern that Herrmann and Brach could hinder their careers.

Earlier this year, however, they took their evidence to a sympathetic intermediary, who alerted the deans of medicine at Ulm and

\section{Computer rolled three sets of data into one}

\footnotetext{
One paper in which Brach admitted falsifying results is in The Journal of Experimental Medicine (181, 793; 1995). This figure, taken from the paper, shows an autoradiogram intended to indicate the intracellular location of transcription factors induced by the cytokine TNF. Yet it is composed of three unrelated sets of data. Also, the pattern of bands in the lanes indicates that one of the autoradiograms has been used twice in creating the figure.

Such manipulation of images is easy to achieve with the help of computers. John Tooze, editor of EMBO Journal, says that the ability to manipulate and enhance digitized images increases the opportunity for fraud, and therefore pressure on scientists reviewing potential journal articles to be more vigilant.
}

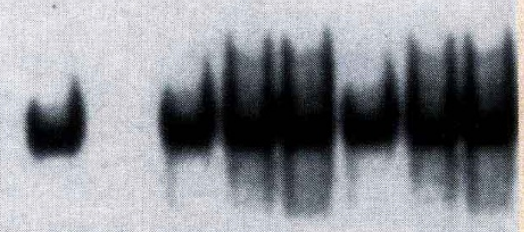

Lübeck universities, as well as Detlev Ganten, director of the Max Delbrück Centre.

Guido Adler, dean of medicine at Ulm, asked Herrmann and Brach for written statements in response to the allegations. Brach is said to have eventually admitted falsifying data in four papers - two in Blood, one in EMBO Journal and one in The Journal of Experimental Medicine - but Herrmann denied involvement.

A local committee of investigation set up by Adler is likely to issue an interim conclusion next week about whether Herrmann was involved. The minister of science in the state of Baden-Württemberg is responsible for deciding what penalty to impose if Herrmann is proved to have been involved. Dismissal is a possibility, says Adler. "But it is hard to know what will happen because we have no experience of this in Germany." Adler has asked Herrmann to voluntarily give up his academic duties until the issue has been resolved.

Herrmann claims that when he was working in Berlin he left the running of the research projects in the hands of his four group leaders. Although he says that he read closely all the papers he co-authored, he did not recognize that data had been forged. "But neither did the journals' referees", says Herrman.

$\mathrm{He}$ argues that the affair has been "hochgekocht" (overplayed), although he says he now accepts that data in at least one of the papers had clearly been fabricated. This is a paper in The Journal of Experimental Medicine about the control of transcription by the cytokine TNF (tumour necrosis factor) in human fibroblasts.

Among other deceptions (see figure), the paper presents as western blots, which are standard protein assays, old (non-radioactive) enzyme assays that had been stored as computer images. Smears of background radioactivity apparently went unnoticed by referees.

Ganten, who is a member of the national committee set up to investigate the affair, says he is astonished and disheartened that the papers appear to have passed through refereeing procedures without difficulty.

The national investigatory committee, made up of scientists and representatives of funding agencies, is studying other publications from the group to determine whether there are any further indications of fraud. It will also consider if grant money used for the fraudulent work should be repaid. It will report in the summer.

Most observers suspect that the deception was provoked by the increasing pressure on researchers in a 'publish-or-perish' environment, as well as the sudden opening of new opportunities in Germany in all areas of applied molecular biology. 